\title{
A CULPABILIZAÇÃO DAS MULHERES VÍTIMAS DE ESTUPRO: UMA ANÁLISE A LUZ DA DOGMÁTICA PENAL E DA PERSPECTIVA DE GÊNERO
}

VICTIM BLAMING OF WOMEN IN RAPE CASES: AN ANALYSIS IN LIGHT OF CRIMINAL DOGMATICS AND GENDER PERSPECTIVE

\section{Nicole El Murr ${ }^{1}$}

USP

\section{Resumo}

O estudo objetiva analisar, de forma crítica, a possibilidade de aplicação da vitimodogmática nos casos de crimes sexuais e de consequente influência do comportamento da vítima na valoração jurídico-penal do delito. Para tanto, a partir da teoria da imputação objetiva, será investigado o instituto da autocolocação em risco e avaliada sua aplicabilidade nos casos em questão; o tópico será também contextualizado, tendo em vista a posição da mulher na sociedade e a perpetuação de práticas discriminatórias por meio do Direito Penal. Conclui-se que a culpabilização da vítima é fruto de uma estrutura social marcada pela disparidade de gênero e não encontra respaldo racional.

Palavras-chave

Mulher. Estupro. Vitimodogmática. Estereótipos. Dogmática penal.

\section{Abstract}

This article aims to analyse, in a critical way, the possibility of applying victimdogmatic in cases of sexual crimes and, as a consequence, the effects of the victim's behavior on legal reasoning. For this purpose, on the basis of the objective imputation theory, the idea of the victim putting herself at risk will be examined in

${ }^{1}$ Graduanda em Direito pela Universidade de São Paulo. 
order to check its validity; the topic will also be contextualized by taking into consideration women's position in society and the perpetuation of discriminatory practices through Criminal Law. It is concluded that victim blaming is a result of gender inequality and has no rational foundation.

\section{Keywords}

Woman. Rape. Victim-dogmatic. Stereotypes. Criminal dogmatics.

\section{INTRODUÇÃO}

Uma das grandes polêmicas que envolvem os crimes sexuais está relacionada ao estudo da vítima e seu comportamento. Nos mais diversos ambientes, é recorrente a discussão acerca da possibilidade de a vítima influir na ocorrência desses delitos.

Nos últimos anos, pesquisas realizadas no Brasil procuraram apurar a opinião da população a respeito das agressões contra mulheres. De acordo com a pesquisa "\#APolíciaPrecisaFalarSobreEstupro", de 2016, realizada pelo Datafolha, 32\% das mulheres e $42 \%$ dos homens entrevistados consideram que "mulheres que se dão ao respeito não são estupradas"2. Pesquisa divulgada em 2014 pelo Instituto de Pesquisa Econômica Aplicada (Ipea), intitulada "Tolerância social à violência contra a

2 Pesquisa "\#APolíciaPrecisaFalarSobreEstupro: Percepção sobre violência sexual e atendimento a mulheres vítimas nas instituições policiais”.

Disponível

em:

http://fopir.org.br/wpcontent/uploads/2017/06/FBSP_Policia_precisa_falar_estupro_2016.pdf Acesso em: 2 set. 2020. 
mulher", revelou que 58,5\% dos entrevistados concordam total ou parcialmente com a afirmação de que "se as mulheres soubessem como se comportar, haveria menos estupros" e $26 \%$, que "mulheres que usam roupas que mostram o corpo merecem ser atacadas"3.

Diante desse cenário, cabe uma investigação sob a ótica do Direito Penal para avaliar (1) em que medida as opiniões mencionadas são refletidas no sistema jurídico-penal e de que forma afetam as vítimas e (2) se há respaldo para a aplicação da vitimodogmática no julgamento dos crimes sexuais. Nesses casos, o emprego da perspectiva vitimodogmática dialogaria com as opiniões apresentadas nas pesquisas e implicaria em uma série de efeitos jurídicos.

A questão permanece atual, tendo em vista a conservação, inclusive no meio jurídico, de práticas discriminatórias e estereótipos sociais relacionados ao tema. Por meio do presente artigo, busca-se fomentar o debate acadêmico acerca da culpabilização das vítimas de estupro, considerando a relevância do assunto na luta pela igualdade de gênero e as sensíveis consequências, na realidade prática, de discursos preconceituosos que ocultam-se sob suposta tecnicidade.

O objetivo do artigo é examinar e problematizar, a partir da contraposição entre determinadas correntes vitimodogmáticas e teorias feministas, os argumentos em favor da

3 Pesquisa "Tolerância social à violência contra as mulheres." Disponível em: https://www.ipea.gov.br/portal/images/stories/PDFs/SIPS/140327_sips_violencia_m ulheres_novo.pdf. Acesso

em: 2 set. 2020. 
responsabilização de mulheres vítimas de crimes sexuais. Para isso, em um primeiro momento, serão aprofundados os aspectos relativos à vitimodogmática; em um segundo momento, serão apresentados elementos da dogmática penal e a autocolocação em risco, instituto pertinente à vítima, relacionando-a com o tema da culpabilização; em um terceiro momento, visando à contextualização do assunto, será apresentada a histórica influência da moralidade no Direito Penal e sua relação com a posição social das mulheres; em um quarto momento, uma análise específica do tema sob a ótica feminista, com a retomada de conceitos e sua concatenação; por fim, será abordado o impacto concreto das visões vitimodogmáticas na vida das mulheres violentadas. Como recorte, será estudado com mais detalhamento o crime de estupro.

\section{A PERSPECTIVA VITIMODOGMÁTICA}

A figura da vítima, no estudo penal, foi tratada com mais ou menos relevância em diferentes contextos históricos. A partir do momento em que os poderes públicos monopolizam a reação penal o que se inicia com a crise do feudalismo e se consolida com a centralização do Estado Moderno -, ocorrem restrições à possibilidade, por parte da vítima, de autotutela de seus interesses. Essa 
nova tessitura histórica e social leva a uma neutralização do poder da vítima e consequente apagamento de sua figura ${ }^{4}$.

A "redescoberta da vítima" (ou, em termos mais adequados, o movimento vitimológico) no processo penal é recente. A vitimologia, como estudo de contorno criminológico, floresceu após a Segunda Guerra Mundial, como reflexo da experiência das vitimizações em massa. Nesse contexto, a vítima passa a ser entendida como uma figura complexa, e seu estudo passa a envolver tanto o indivíduo quanto a relação autor-vítima ${ }^{5}$.

O estudo vitimológico abre espaço para a análise do papel da vítima no ato delitivo, partindo-se do pressuposto de que a vítima não ocupa uma posição estritamente passiva. Nesse cenário, insere-se a vitimodogmática, ramo que busca examinar em que medida o delito é resultado da interação entre delinquente e vítima. Sob essa ótica, surge uma importante consequência: o comportamento da vítima poderia repercutir na valoração jurídico-penal do comportamento do autor ${ }^{6}$. Dependendo do ponto de vista, tal análise poderia influenciar na determinação da pena judicial do autor ou mesmo isentar a responsabilidade do autor, com a exclusão do tipo ${ }^{7}$.

${ }^{4}$ SHECAIRA, Sérgio Salomão. Criminologia. 3. ed. São Paulo: Revista dos Tribunais, 2011, p. 51.

${ }^{5}$ Ibidem, p. 52-53.

${ }^{6}$ SALGADO, Amanda Bessoni Boudoux; MACRI JR, José Roberto. Raça e Violência Sexual: âmbito de Aplicação da Vitimodogmática? Cadernos de Estudos Sociais e Políticos: Interface entre gênero, raça e classe social, 2017, p. 50.

7 FONSECA, Ana Clara Montenegro. Conduta da vítima de crime na dogmática penal: análise crítica sobre a posição da vítima na aferição da responsabilidade penal 
Nas palavras de Sydow,

diversos tipos penais admitem que a vítima possa ter participação ativa no cometimento do fato, porquanto pode agir de modo provocativo, ser desidiosa quanto aos seus deveres de cuidado, contribuir para $o$ acontecimento lesivo e até mesmo confundir-se com a figura do lesionador ${ }^{8}$.

Pode-se afirmar, portanto, que o debate apresentado na introdução está intimamente relacionado ao questionamento: os crimes sexuais (em evidência, o estupro) enquadrariam-se nos tipos descritos pelo excerto supracitado?

Diferentes correntes doutrinárias oferecem respostas a essa questão9. Uma corrente afirma serem impertinentes discussões vitimodogmáticas acerca do tema, sob risco de incorrer em danos sociais e político-criminais (perda de confiança no direito penal) e em desmedida culpabilização da vítima. Uma perspectiva intermediária considera a aplicação dos postulados da vitimodogmática em circunstâncias específicas, quando, por exemplo, a iniciativa da relação

do autor à luz da vitimodogmática e da imputação à vítima. Dissertação de Mestrado em Direito. Centro de Ciências Jurídicas. Universidade Federal de Pernambuco, 2009, p. 61 e 67.

${ }^{8}$ SYDOW, Spencer Toth. Delitos informáticos próprios: uma abordagem sob a perspectiva vitimodogmática. Dissertação de Mestrado em Direito. Faculdade de Direito. Universidade de São Paulo, 2009, p. 148.

${ }^{9}$ SALGADO, Amanda Bessoni Boudoux; MACRI JR, José Roberto. Raça e Violência Sexual: âmbito de Aplicação da Vitimodogmática?, op. cit., p. 53-54. 
sexual parte da vítima. Outra linha de pensamento, já considerada ultrapassada, julga o comportamento da vítima como determinante para a ocorrência do estupro. Nessa perspectiva, seriam fatores relevantes a serem considerados sua vestimenta, seu modo de agir, seu histórico sexual, entre outros.

Um primeiro aspecto no qual os adeptos dessa corrente costumam basear-se é o conceito de "vítima provocadora", apresentada por Benjamin Mendelsohn, considerado o fundador do movimento vitimológico. Mendelsohn definiu diferentes categorias de vítimas, como forma de quantificar a influência das mesmas no delito. Conforme essa classificação, a vítima provocadora teria participação certa no ato e seria tão responsável quanto o agente ${ }^{10}$. Aproximando o conceito da esfera dos crimes sexuais, afirma Souza que uma vítima provocadora seria:

[...] aquela que, sob a influência de móveis estritamente pessoais, teleologicamente afinados com o vitimizador, e determinados por suas idiossincrasias sexuais, deflagra um processo sinalagmático de estimulação de respostas por parte do vitimizador, as quais vêm a se constituir, no limite, em projeção, sobre a pessoa da vítima, de atos/fatos produzidos pelo vitimizador na esfera de sua sexualidade ${ }^{11}$.

${ }^{10}$ SYDOW, Spencer Toth. Delitos informáticos próprios, op. cit., 2009, p. 150.

11 SOUZA, José Guilherme de. Vitimologia e Violência nos crimes sexuais: uma abordagem interdisciplinar.

Porto Alegre: Sérgio Antonio Fabris Editor, 1998, p. 85. 
Outro aspecto mencionado por essa corrente seria a suposta existência de um "consentimento tácito" entre autor e vítima ${ }^{12}$. Segundo autores dessa corrente, ocorreria um erro de comunicação entre os indivíduos envolvidos que propiciaria a ocorrência do delito. Dessa forma, o comportamento da vítima poderia representar, na visão do delinquente, uma implícita concordância em manter relações sexuais, ainda que a vítima tenha insistido em uma negativa. Nesse sentido, afirma Menachem Amir:

$\mathrm{Na}$ esfera sexual, um homem pode interpretar comportamento verbal e não verbal por parte de uma mulher como contrário às expectativas sobre o apropriado comportamento feminino, ou mesmo conflitante com a imagem do decoro feminino. Ela será posicionada, então, na categoria de uma mulher sexualmente disponível. Dessa forma, erroneamente ou não, o comportamento de uma mulher, se passivo, pode ser digno a ponto de caber ação e, se ativo, pode ser considerado como uma verdadeira promessa de sucesso para as intenções sexuais de alguém. O ofensor reagirá, então, conforme parecer apropriado em relação a uma mulher como essa ${ }^{13}$.

${ }^{12}$ SALGADO, Amanda Bessoni Boudoux; MACRI JR, José Roberto. Raça e Violência Sexual: âmbito de Aplicação da Vitimodogmática?, op. cit., p. 54.

${ }^{13}$ AMIR, Menachem. Victim Precipitated Forcible Rape. Journal of Criminal Law and Criminology,

vol. 58, Issue 4, 1968, p. 494. Tradução nossa. 
Essa lógica busca evidenciar (1) a possibilidade de responsabilização da vítima e (2) seus supostos deveres de autoproteção. Antes de nos aprofundarmos em uma crítica à última corrente apresentada, portanto, cabe abordarmos a autocolocação em risco, muitas vezes mencionada como fundamento dogmático para tais opiniões.

\section{A AUTOCOLOCAÇÃO EM RISCO}

Como pontua Luís Greco, a imputação objetiva enuncia "o conjunto de pressupostos genéricos que fazem de causação objetivamente típica; e estes pressupostos são a criação de um risco juridicamente desaprovado e a realização deste risco no resultado" ${ }^{14}$. O conceito ultrapassa, portanto, as meras relações de causalidade. Há a possibilidade, nesse contexto, de exclusão da desaprovação jurídica de um risco, campo em que se insere a análise da colocação em perigo. Nessa situação, o comportamento da vítima é determinante na avaliação da tipicidade.

A autocolocação em risco constitui uma exposição, criação ou mesmo omissão diante do perigo pelo titular do bem jurídico. As condutas arriscadas, portanto, seriam livremente assumidas pelo ofendido no exercício de sua autonomia, tornando-se

${ }^{14}$ GRECO, Luís. Um panorama da teoria da imputação objetiva. 4. ed. São Paulo: Revista dos Tribunais, 2014, p. 26. 
responsável pelo resultado ${ }^{15}$. Além disso, é importante destacar que o risco deve acarretar de forma direta e imediata no resultado lesivo ${ }^{16}$.

Ao analisar o alcance do tipo, Roxin ilustra a autocolocação em risco com a seguinte situação: A vende heroína para B; ambos estavam cientes da possibilidade de overdose decorrente do uso da droga; B vem a falecer, sendo a causa direta da morte a injeção de heroína em seu corpo. Surge o questionamento: seria cabível condenar A por homicídio? O autor afirma que, nesse caso, não basta a consideração das relações de causalidade - segundo a qual a entrega de heroína por parte de A de fato ocasionou a morte. Deve-se observar que a vítima conhecia o risco e o assumiu, sendo aplicável o princípio da auto responsabilidade. ${ }^{17}$

Nos crimes sexuais, como já mencionado, a autocolocação em risco é frequentemente invocada: o consumo de álcool, escolha de vestuário, ambientes frequentados pela vítima são muitas vezes considerados como a assunção de um risco, tendo o ofendido controle de sua ação. Porém, há uma série de objeções a serem feitas acerca dessa interpretação, com base em apreciações dogmáticas.

O primeiro aspecto a ser considerado é a própria definição de risco. No exemplo abordado por Roxin, o risco está

15 ANGELI, Ivan Wagner. Ofendido e risco: autocolocação em risco e heterocolocação em risco consentida. Tese de Doutorado em Direito. Universidade de São Paulo, 2018, p. 142.

${ }^{16}$ Ibidem, p. 145-146.

${ }^{17}$ ROXIN, Claus. A Teoria da Imputação Objetiva. Chengchi Law Review, v. 58, mai. 1994, p. 108-109. 
diretamente relacionado com o efeito da substância psicoativa que, por suas propriedades, conduziu ao resultado danoso. Ao tratar-se de um caso de um crime sexual como o estupro, contudo, a situação não é equiparável: a ação lesiva parte de um sujeito que tem autonomia em sua decisão e que deliberadamente opta por realizar o ato. Não se pode assumir o resultado como uma consequência natural do comportamento da vítima, como um acaso tornado provável pela aceitação do risco, uma vez que não se trata de uma eventualidade tão incontrolável quanto o efeito da droga no organismo humano.

Outro tópico é o aspecto subjetivo da autocolocação em perigo. Nas palavras de Angeli, para que a auto-responsabilidade se configure, "no campo da vontade, deve o sujeito querer colocar seus bens jurídicos frente ao risco conhecido" 18 , além de ter conhecimento sobre o perigo. A questão do bem jurídico tutelado pelos crimes sexuais é controversa; pode-se constatar, no entanto, que a tendência é sua desvinculação da esfera moral. Nessa linha, o bem jurídico protegido seria a autodeterminação sexual, dando-se ênfase à liberdade de cada indivíduo e não a uma honra sexual pautada pela moralidade. A partir desse enfoque, não se poderia confundir as escolhas de uma mulher referentes à sua vida social e sexual - com o desejo de ter a autodeterminação sexual ferida, sendo descaracterizada a autocolocação em perigo.

Além disso, deve-se verificar se a conduta da vítima apresenta uma correspondência imediata, relevante e direta com o resultado. Como já mencionado, uma vez que o estupro é um ato que

${ }^{18}$ ANGELI, Ivan Wagner. Ofendido e risco, op. cit., p. 146. 
depende de um agente, intermediado por sua esfera psicológica, é ilógico afirmar uma causalidade direta entre a conduta da vítima e a lesão, de forma a deslegitimar a punição do infrator. A criação de um nexo direto entre os dois fatos é mera elaboração valorativa, condicionada pelo fundo cultural da sociedade na qual estamos inseridos.

A partir da breve análise realizada, pode-se concluir que a alegação de autocolocação em perigo nesses casos dissimula a atuação do ofensor e desloca o foco da questão. São evidentes valorações morais, filtros sociais nessa espécie de argumento, através dos quais atitudes comuns, alicerçadas nas liberdades individuais (como a escolha de vestimentas e modo de vida) são enxergadas de forma negativa, como inaceitáveis, reprováveis. Nesse ponto, é essencial a compreensão da estrutura na qual estão inseridas essas concepções morais; começaremos por identificar a possibilidade de influência da moral no campo do Direito Penal, trazendo uma perspectiva histórica.

\section{A MORAL E O DIREITO PENAL}

Até 2009, no Brasil, o Código Penal enquadrava os crimes sexuais sob o título "dos crimes contra os costumes", enfatizando o viés moral que perpassava as valorações jurídico-penais. Nesse contexto, a concepção do bem jurídico ofendido não priorizava a liberdade da vítima, mas englobava uma série de valores morais que regulavam a vida em sociedade: de forma rígida, a honra sexual de uma mulher importava não somente à sua posição e aceitação social, mas também à honra de sua família. 
Essa concepção é ilustrada no emprego do termo "mulher honesta" nos artigos 215, 216 e 219 do Código Penal brasileiro, alterado pela recente Lei n. 11.106 de 2005. O conceito implicava na proteção exclusiva às mulheres "cuja conduta, sob o ponto de vista da moral sexual, é irrepreensível" e que não romperam "com o minimum de decência exigida pelos bons costumes"19, nas palavras de Hungria, autor do anteprojeto de 1969 do Código.

A consequência dessa nomenclatura, presente desde as Ordenações Filipinas, era a desproteção de todas as mulheres marginalizadas socialmente por critérios morais. Ainda conforme Nelson Hungria,

Só deixa de ser honesta (sob o prisma jurídico-penal) a mulher francamente desregrada, aquela que inescrupulosamente, [...] ainda não tenha descido à condição de autêntica prostituta. Desonesta é a mulher fácil, que se entrega a uns e outros, por interesse ou mera depravação $[\ldots]^{20}$.

Seria possível afirmar que tal desproteção não apenas se prestava a uma punição indireta dessas figuras, deslegitimando sua posição como vítimas, como também era fruto da pressuposição do risco assumido por elas, eximindo a responsabilidade do autor.

O moralismo teve outros reflexos jurídicos no Brasil, como por exemplo a inexistência do crime caso a mulher vítima de violência

${ }^{19}$ HUNGRIA, Nelson. Comentários ao Código Penal. 5 ed. Rio de Janeiro: Forense, 1981. v. 8.

${ }^{20}$ Ibidem. 
sexual se casasse com seu agressor ou com terceiro - e não requeresse o prosseguimento do inquérito policial dentro do prazo estipulado conforme o artigo 107, incisos VII e VIII; a redução de um terço da pena se o rapto da vítima tivesse como fim o casamento (artigo 221) ${ }^{21}$; e a exclusão do tipo em casos de "crimes passionais", nos quais o marido tirava a vida da esposa alegando seu adultério. Tais situações demonstram o papel secundário da mulher e de sua individualidade, reafirmando a figura do homem como polo social.

O debate acerca da ingerência da esfera moral no Direito Penal persistiu mesmo com a consolidação do paradigma do Estado liberal e do positivismo jurídico. O dilema, que envolvia a legitimidade da criminalização de condutas imorais no campo sexual, também pode ser utilizado como referência quando é a vítima quem arca com as condenações morais.

Roxin posiciona-se em prol de um Direito Penal mínimo, que proíba apenas o necessário para se assegurar uma "convivência pacífica, livre e igualitária entre os homens"22. Dessa forma, a punição estatal encontraria limites na própria finalidade do Direito Penal, não encontrando fundamento na ética, na moral, na religião ou em questões ideológicas. Como consequência dessa visão, temos a ilegitimidade das sanções a imoralidades e condutas reprováveis na ausência de uma efetiva lesão a bens jurídicos; aquilo que não tem repercussões danosas à vida em sociedade e desenrola-se no âmbito

${ }^{21}$ Esses dispositivos foram revogados pela Lei n. 11.106/05, assim como os artigos referentes ao crime de adultério e sedução.

${ }^{22}$ ROXIN, Claus. Estudos de Direito Penal. Rio de Janeiro: Renovar, 2006, p. 31-34. 
privado do indivíduo não é passível de punição, considerando os valores da liberdade e da autonomia.

A análise pessoal e subjetiva da figura da vítima baseia-se em critérios estritamente morais. Nessa perspectiva, a redução da responsabilidade do autor do delito alicerçada nesses preceitos pode ser interpretada mesmo como uma forma de punição da vítima por seu comportamento, por supostos descuidos, invalidando a lesão sofrida e agregando à valoração o exame de elementos juridicamente irrelevantes. Enquanto isso, o ato do delinquente, verdadeiramente prejudicial à coexistência igualitária referida por Roxin e à liberdade individual, teria sua gravidade reduzida por aspectos superficiais e pouco técnicos.

O cerne da questão, portanto, é o "não reconhecimento da mulher como sujeito direito e titular de um direito violado" 23 com base em estereótipos de gênero.

\section{TODAS AS MULHERES SÃO CONSIDERADAS VÍTIMAS?}

O estupro - e todas as questões que engloba - não se restringe à violação da autodeterminação sexual. Embora o tipo penal tenha deixado de limitar o sujeito passivo do crime à mulher, com a edição da Lei n. 12.015, é possível afirmar que a maioria dos casos

${ }^{23}$ SALGADO, Amanda Bessoni Boudoux; MACRI JR, José Roberto. Raça e Violência Sexual: âmbito de Aplicação da Vitimodogmática?, op. cit., p. 55. 
envolve a violência praticada por um homem contra uma mulher ${ }^{24}$. A violência sexual contra as mulheres é indissociável da desigualdade de gênero; trata-se de um dos sintomas da estrutura social, sendo marcante a influência da cultura na ocorrência do crime.

Foi cunhado o termo "violência de gênero" para referirse às práticas de agressão, psicológicas, físicas e sexuais, dirigidas às mulheres e inseridas na estrutura patriarcal, definidora das relações de poder. A origem dessa violência, de acordo com María Luisa Maqueda Abreu, não é biológica ou doméstica; trata-se de uma situação de discriminação intertemporal, derivada da cultura:

O gênero se constitui, assim, no resultado de um processo de construção social mediante o qual se adjudicam simbolicamente as expectativas e valores que cada cultura atribui a seus homens e mulheres. Fruto dessa aprendizagem cultural de cunho machista, eles e elas exibem os papéis e identidades que lhes foram designados sob a etiqueta do gênero. Por essa razão, a prepotência do masculino e a subalternidade do feminino são os ingredientes essenciais dessa ordem simbólica que define as relações de poder dos homens sobre as mulheres, origem da violência de gênero. ${ }^{25}$

24 ALMEIDA, Gabriela Perissinotto de. Estereótipos de gênero sobre mulheres vítimas de estupro: uma abordagem a partir do viés de gênero e dos estudos de teóricas feministas do direito. Dissertação de Mestrado em

Direito. Faculdade de Direito de Ribeirão Preto. Universidade de São Paulo, 2017, p. 73.

${ }^{25}$ MAQUEDA ABREU, María Luisa. La violencia de género: entre el concepto jurídico y la realidad social. Revista Electrónica de Ciencia Penal y Criminología, n. 8, 2006, p. 2. Tradução nossa. 
Seria um erro, portanto, reduzir a interpretação da violência a casos individuais, atribuindo-a exclusivamente a circunstâncias ambientais, ao uso de álcool/entorpecentes, à relação sentimental entre vítima-agressor, às suas personalidades, entre outros fatores.

A questão identitária, evidenciada na existência dos gender roles, é essencial para a compreensão do fenômeno de culpabilização da vítima nos casos de estupro. A base da estrutura patriarcal é a dominação da mulher pelo homem, implicando na submissão e respeito à autoridade masculina. A manutenção dessa conformação também ocorre por meio dos estereótipos de gênero.

Os estereótipos de gênero são imagens preconcebidas que reúnem as características e atributos ideais para cada gênero, visando às funções sociais a serem desempenhadas ele; envolvem, portanto, modelos de comportamento. A representação da mulher oscila entre dois extremos: a mulher digna e respeitável em oposição à mulher depravada moralmente. De acordo com Coulouris, historicamente,

[...] a configuração do conceito de mulher honesta compreendia a forma de se comportar socialmente, as roupas utilizadas, o tipo de trabalho que realizavam, o ambiente social que frequentavam ou em que residiam, sua adequação à moral sexual discursivamente prescrita em textos legais, orientações religiosas, médicas, familiares, educativas, manuais de etiqueta social e 
revistas femininas populares no Brasil desde o início do século XX. ${ }^{26}$

A distinção entre as virtudes e vícios pelos indivíduos nesse campo (assim como em qualquer outro) ocorre por meio da convivência social, da educação, e também dos veículos culturais, como livros, filmes, propagandas, etc. São distintos entre si (1) os estereótipos de gênero, de caráter prescritivo, e (2) os estereótipos de vítima. A culpabilização da vítima pode basear-se tanto na negação do dever-ser (como, por exemplo, a promiscuidade), quanto em arquétipos femininos de conotação negativa (mulher dissimulada, manipuladora, vingativa, louca, sedutora).

O discernimento do bom e do mau tem consequências na esfera psicológica das vítimas de crimes sexuais, considerando a fixação desses valores no oprimido. Dessa forma, além de contribuir para a incompreensão da sociedade e estigmatização da vítima aos seus olhos, colabora para a criação do sentimento de culpa na mulher ofendida, que considera-se responsável pela lesão. Ademais, a naturalização da violência de gênero e a permissividade social do mau-trato ${ }^{27}$ eventualmente dificultam a compreensão e identificação da lesão sofrida por parte da vítima.

${ }^{26}$ COULOURIS, Daniella Georges. A desconfiança em relação à palavra da vítima $\mathbf{e}$ o sentido da punição em processos judiciais de estupro, Tese de Doutorado em Sociologia. Faculdade de Filosofia, Letras e Ciências Humanas. Universidade de São Paulo, 2010, p. 121.

${ }^{27}$ MAQUEDA ABREU, María Luisa. La violencia de género, op. cit., p. 6. 
A comparação entre o dever-ser designado à mulher - de caráter universalista e essencialista - e a conduta da vítima, em senso comum, não é apenas utilizada como critério para a determinação de veracidade das alegações proferidas contra o acusado: pode prestar-se também à valoração dos acontecimentos, isto é, à certificação de que o ocorrido "de fato" configura um estupro. Aqui, insere-se outra discussão: a existência dos estereótipos que circundam o crime do estupro e o criminoso.

O crime de estupro é caracterizado pela ausência de consentimento para a prática sexual. No entanto, socialmente, ocorre a circulação de "representações pouco flexíveis sobre a imagem da vítima, do agressor e da reação à agressão" 2 . Alguns exemplos disso seriam a falsa crença de que, para que se configure o estupro, deva ocorrer extrema resistência por parte da vítima; de que o corpo encontrar-se-á gravemente lesionado; e de que a denúncia, para ser legítima, tenha ocorrido logo após o acontecimento ${ }^{29}$. Quando há familiaridade entre o agressor e a vítima, maiores as dificuldades probatórias, e não necessariamente menos danoso, traumático o acontecimento. Vale lembrar que, em um passado recente, o ato entre marido e esposa não era considerado estupro ${ }^{30}$.

${ }^{28}$ ALMEIDA, Gabriela Perissinotto de. Estereótipos de gênero sobre mulheres vítimas de estupro, op. cit., p. 75.

${ }^{29}$ Ibidem, p. 76.

${ }^{30}$ SALGADO, Amanda Bessoni Boudoux; MACRI JR, José Roberto. Raça e Violência Sexual: âmbito de Aplicação da Vitimodogmática?, op. cit., p. 52. 
Nesse sentido, nem todas as mulheres são consideradas vítimas.

[...] quando a vítima não for considerada recatada e respeitável, quando conhecer o agressor, quando não estiver sóbria, quando não tiver resistido ou não puder provar que resistiu, ou quando não tiver denunciado o crime imediatamente à polícia, não será avaliada como vítima genuína ${ }^{31}$.

É essencial, para o aprofundamento do tema, o estudo das questões raciais, que também influem para o reconhecimento do indivíduo como vítima.

O estereótipo do criminoso também contribui para a deslegitimação da posição da vítima. O "verdadeiro estuprador" seria anormal, patológico, marginalizado da sociedade, desconhecido pela ofendida. ${ }^{32}$ Entretanto, o criminoso pode ter as mais variadas características; a dificuldade de reconhecê-lo pode residir no fato, por exemplo, de o ofensor pertencer à mesma classe social da vítima, circular nos mesmos ambientes, pertencer a uma família estruturada, etc. O estupro, afinal, é marcado pelas discrepâncias de poder, definidas pelo gênero, que perpassam os mais variados setores sociais.

31 ALMEIDA, Gabriela Perissinotto de. Estereótipos de gênero sobre mulheres vítimas de estupro, op. cit., p. 76.

32 ALMEIDA, Gabriela Perissinotto de. Estereótipos de gênero sobre mulheres vítimas de estupro, op. cit., p. 76. 
Além disso, a aferição do consentimento é muitas vezes abordada de forma errônea. Autores como Souza consideram a possibilidade de um consentimento tácito, no qual o comportamento da vítima indicaria a disposição para realizar o ato sexual. Como já mencionado, tal pressuposição ampara-se tão somente na relação de dominação homem-mulher, que exige a submissão da vítima como fonte de prazer, e em estereótipos femininos. Os "jogos de sedução" também são frequentemente invocados para enfatizar o "consentimento tácito"; porém, a recusa permanece sendo a máxima expressão da vontade da vítima, e basta para aferir se a relação é consentida ou não.

Um trecho que ilustra esses e outros estereótipos foi redigido por Bittencourt:

[...] nem sempre a posse por violência irresistível constitui crime: é o caso, por exemplo, em que a mulher espontaneamente aquiesce em entregar-se, ou mesmo solicita o homem, mas em arrependimento tardio, recusa-se no momento da aproximação dos sexos, quando aquele já se encontra no desespero de sua vontade. Os atos de violência, aí, só serão punidos quando constituírem delito diferente do de natureza sexual. Também não basta uma platônica ausência de adesão, uma recusa meramente verbal; o dissenso da vítima [...], deve ser sincero e positivo, manifestando-se por inequívoca resistência, através de uma vontade decidida 
e militantemente contrária, de uma oposição que só a violência física ou moral consiga vencer. ${ }^{33}$

$\mathrm{O}$ excerto introduz à análise a impulsividade sexual e consequente redução de responsabilidade. A concepção é errônea e enviesada: o pressuposto que o agente não tem controle sobre instintos naturais contradiz a existência de mecanismos sociais de controle e a própria finalidade do sistema penal. Seguindo a mesma lógica, todos os demais delitos seriam igualmente fruto de impulsos naturais (de sobrevivência, de fúria, etc.). $\mathrm{O}$ argumento que se baseia na inevitabilidade do ato sexual apenas reforça o conjunto de ideias já explorado, tornando secundária a subjetividade e autodeterminação da mulher.

Nesse contexto, os deveres de proteção atribuídos à vítima perdem legitimidade. Sob essa ótica, aquilo que consiste o mero exercício de liberdades é visto como prescindível e até mesmo condenável, algo incompatível em um Estado pautado pela isonomia. Ademais, como já mencionado, o nexo de causalidade entre a conduta e a suposta consequência é vago e tendencioso. Faz-se necessário, portanto, "delimitar o âmbito de aplicação da vitimodogmática", tendo em vista o dilema entre a sobrecarga da vítima com deveres de

33 BITTENCOURT, Edgard de Moura. Vítima: vitimologia, a dupla penal delinquente-vítima, participação da vítima no crime, contribuição da jurisprudência brasileira para a nova doutrina. 5. ed. São Paulo: Universitária de Direito, 1971, p. 183-184. 
proteção e casos em que a ampla responsabilização do autor torna-se desproporcional ${ }^{34}$.

\section{AS CONSEQUÊNCIAS DA RESPONSABILIZAÇÃO DA VÍTIMA}

A culpabilização da vítima pela visão comum, endossada por alguns juristas, acarreta em consequências no tratamento dispensado às mulheres ofendidas. Por tratar-se de uma questão extremamente delicada, um crime de acentuada violência, que envolve a esfera psicológica do indivíduo - ocasionando possíveis traumas - e reações sociais, faz-se essencial uma aproximação criteriosa da vítima, que ampare sua integridade.

Uma das principais consequências do enraizamento dessa ótica é o receio da vítima em denunciar o crime. $\mathrm{O}$ acesso à Justiça, nesses casos, é prejudicado pelos sentimentos da vítima (culpa, vergonha, humilhação, excessiva exposição de sua privacidade, entre outros já mencionados anteriormente, frutos da estrutura social) e pela incerteza/ausência de apoio e compreensão por parte da sociedade. Além disso, como já abordado, muitas vezes a própria vítima não se enxerga como vítima, devido à absorção dos valores sociais. Decorre desses fatores a subnotificação dos crimes de estupro e abuso sexual, gerando a chamada cifra negra da criminalidade, ou seja, a porcentagem de delitos não averiguados. ${ }^{35}$ Segundo a Pesquisa

${ }^{34}$ SALGADO, Amanda Bessoni Boudoux; MACRI JR, José Roberto. Raça e Violência Sexual: âmbito de Aplicação da Vitimodogmática?, op. cit., p. 50.

35 SHECAIRA, Sérgio Salomão. Criminologia, op. cit., p. 54. 
Nacional de Vitimização (2013), realizada no Brasil, "do total de vítimas de ofensas sexuais nos 12 meses anteriores à pesquisa, apenas $7,5 \%$ deram queixa do ocorrido à polícia" ${ }^{36}$.

Outras consequências surgem quando a denúncia é efetuada. Há inúmeras adversidades intrínsecas ao atual sistema judiciário, como a dificuldade da vítima em suportar psicologicamente um processo e a postura do aparelho estatal (descaso, desconfiança, exaustivas oitivas, exigência de uma excessiva coerência de detalhes muitas vezes infactível), em conformidade com a tendência de descrédito à palavra da vítima. Essa situação é referida como vitimização secundária, definida por Shecaira como:

[...] um derivativo das relações existentes entre as vítimas primárias e o Estado em face do aparato repressivo (polícia, burocratização do sistema, falta de sensibilidade dos operadores do direito envolvidos com alguns processos bastante delicados etc. $)^{37}$,

A ser combatida por meio de um maior preparo dos agentes públicos, ampliação das formas de assistência, entre outras medidas. Ademais, a vitimização terciária sofrida pelas ofendidas estaria "vinculada à falta de amparo do Estado e da ausência de receptividade

36 "Pesquisa Nacional de Vitimização (2013)", p. 193. Disponível em: https://www.novo.justica.gov.br/sua-seguranca-2/seguranca-publica/analise-epesquisa/estudos-e-pesquisas/estudos-e-pesquisas. Acesso em: 2 set. 2020.

${ }^{37}$ SHECAIRA, Sérgio Salomão. Criminologia, op. cit., p. 55. 
social"38. Todos esses fatores inibem o interesse da vítima na persecução penal e são danosos à saúde mental da vítima.

Pode ocorrer, outrossim, uma "perda de confiança no direito penal", culminando em prejuízos sociais, posto que a vítima passa a sentir-se sobrecarregada de deveres de autoproteção ${ }^{39}$.

\section{CONSIDERAÇÕES FINAIS}

Embora a corrente doutrinária abordada - que considera a autocolocação em risco um instituto plenamente aplicável aos crimes sexuais - seja considerada ultrapassada por muitos, isso não significa a irrelevância de seu estudo: em primeiro lugar, trata-se de uma corrente recente no Brasil; em segundo lugar, é simultaneamente de um reflexo e fundamento de lugares comuns, arraigados na sociedade. Atualmente, ainda há indivíduos adeptos a essa tese que publicam artigos em sites de conteúdo jurídico e embasam seus textos nos "argumentos de autoridade" dos autores mencionados, como forma de transmitir uma ideia de tecnicidade.

A discussão do tema é extremamente importante em termos estruturais e conjunturais. Um dos propósitos do debate é

38 RODRIGUES, Roger de Melo. A vítima e o processo penal brasileiro: novas perspectivas. Dissertação de Mestrado em Direito. Universidade de São Paulo, 2013, p. 40.

39 SALGADO, Amanda Bessoni Boudoux; MACRI JR, José Roberto. Raça e Violência Sexual: âmbito de Aplicação da Vitimodogmática?, op. cit., p. 53. 
evidenciar a realidade social, conscientizar, para que concepções morais e preconceitos não sejam determinantes no tratamento dispensado às vítimas e nas sentenças judiciais proferidas. Os juízes são parte da sociedade, indivíduos com convicções próprias, e frequentemente reproduzem estereótipos sociais, mesmo que de forma inconsciente.

Nos casos de crimes sexuais, o estudo das vítimas permanece essencial, inclusive para a promoção de políticas criminais. No entanto, é possível afirmar que outras faces da vitimologia, que não o da vitimodogmática, nesse contexto, são mais adequadas de serem enfatizadas.

O crime de estupro é um tema delicado por sua dificuldade probatória, além de relacionar-se à complexa rede de fatores sociais e psicológicos. Entretanto, ao contrário do que é constantemente alegado, as considerações sobre a não culpabilização da vítima não implicam em uma condenação prima facie do acusado. O que é observável em debates atuais acerca do assunto é a pronta invocação do princípio de presunção de inocência em nome do réu e simultâneo ceticismo direcionado à vítima, o que não significa um viés imparcial. A proteção do acusado e do condenado deve ocorrer, em conformidade com as garantias constitucionais; porém, é igualmente inaceitável a desproteção da vítima; isso significaria tornar desassistidas, vulneráveis, milhões de mulheres mediante uma análise arbitrária de seu perfil e opções de vida. Ademais, a consciência acerca da posição da vítima não significa o incentivo ao encarceramento e agravamento das penas como estratégias eficientes para a resolução do problema (constituindo um populismo penal); apenas auxilia em uma 
compreensão mais ampla da sociedade, que permita mudanças nos mais diversos âmbitos.

\section{REFERÊNCIAS}

ALMEIDA, Gabriela Perissinotto de. Estereótipos de gênero sobre mulheres vítimas de estupro: uma abordagem a partir do viés de gênero e dos estudos de teóricas feministas do Direito. 2017. Dissertação (Mestrado em Desenvolvimento no Estado Democrático de Direito) - Faculdade de Direito de Ribeirão Preto, Universidade de São Paulo, Ribeirão Preto, 2017. doi:10.11606/D.107.2019.tde05022019-093155. Acesso em: 2 set. 2020.

AMIR, Menachem. "Victim Precipitated Forcible Rape". Journal of Criminal Law and Criminology, Estados Unidos, v. 58, n. 4, 1968. Disponível em: https://scholarlycommons.law.northwestern.edu/cgi/viewcontent.cgi ?article $=5481 \&$ context $=$ jclc. Acesso em: 2 set. 2020.

ANGELI, Ivan Wagner. Ofendido e risco: autocolocação em risco e heterocolocação em risco consentida. Orientador: Ana Elisa Liberatore Silva. 2018. Dissertação (Doutorado em Direito) - Faculdade de Direito da Universidade de São Paulo, São Paulo, 2018. Disponível em: https://edisciplinas.usp.br/pluginfile.php/5354615/mod_resource/con tent/3/ANGELI\%2C\%20Ivan\%20Wagner.\%20Ofendido\%20e\%20ris co.\%20Autocoloca $\%$ C3\%A7\%C3\%A3o\%20em\%20risco\%20e\%20het erocoloca\%C3\%A7\%C3\%A3o\%20em\%20risco\%20consentida..pdf. Acesso em: 2 set. 2020. 
BITTENCOURT, Edgard de Moura. Vítima: vitimologia, a dupla penal delinquente-vítima, participação da vítima no crime, contribuição da jurisprudência brasileira para a nova doutrina, São Paulo, Universitária de Direito, 1971.

COULOURIS, Daniella Georges. A desconfiança em relação à palavra da vítima e o sentido da punição em processos judiciais de estupro. Orientador: Marcos Cesar Alvarez. 2010. 242 f. Tese (Doutorado) Faculdade de Filosofia, Letras e Ciências Humanas, Universidade de São Paulo, São Paulo, 2010. Disponível em: https:/teses.usp.br/teses/disponiveis/8/8132/tde-20092010155706/publico/2010_DaniellaGeorgesCoulouris.pdf. Acesso em: 2 set. 2020.

FONSECA, Ana Clara Montenegro. Conduta da vítima de crime na dogmática penal: análise crítica sobre a posição da vítima na aferição da responsabilidade penal do autor à luz da vitimodogmática e da imputação à vítima. Orientador: Ricardo de Brito Albuquerque Pontes Freitas. 2009. 164 p. Dissertação (Mestrado em Direito) - Faculdade de Direito do Recife, São Paulo, 2009. Disponível em: https://repositorio.ufpe.br/bitstream/123456789/4736/1/arquivo6332_ 1.pdf. Acesso em: 2 set. 2020.

FÓRUM BRASILEIRO DE SEGURANÇA PÚBLICA; INSTITUTO DE PESQUISA DATAFOLHA. \#APolíciaPrecisaFalarSobreEstupro: Percepção sobre violência sexual e atendimento a mulheres vítimas nas instituições policiais. 2016. Disponível em: http://fopir.org.br/wp- 
content/uploads/2017/06/FBSP_Policia_precisa_falar_estupro_2016.p df. Acesso em: 2 set. 2020.

FREITAS, Elaine Aires. Vitimologia e a mulher enquanto vítima do crime de estupro. Orientador: Antonio Coêlho Soares Junior. 2018. 63 p. Monografia (Bacharelado em Direito) - Universidade Federal do Maranhão, Maranhão, 2018. Disponível em: https://monografias.ufma.br/jspui/bitstream/123456789/2573/1/Elain eFreitas.pdf. Acesso em: 2 set. 2020.

GRECO, Luís. Um panorama da teoria da imputação objetiva, São Paulo, Revista dos Tribunais, 2014.

HUNGRIA, Nelson. Comentários ao Código Penal, Rio de Janeiro, Forense, 1981. v. 8.

INSTITUTO DE PESQUISA ECONÔMICA APLICADA. Tolerância social à violência contra as mulheres, 2014. Disponível em: https://www.ipea.gov.br/portal/images/stories/PDFs/SIPS/140327_sip s_violencia_mulheres_novo.pdf. Acesso em: 2 set. 2020.

INSTITUTO DE PESQUISA DATAFOLHA; CENTRO DE ESTUDOS DE CRIMINALIDADE E SEGURANÇA PÚBLICA. Pesquisa Nacional de Vitimização, 2013. Disponível em: https://www.novo.justica.gov.br/sua-seguranca-2/segurancapublica/analise-e-pesquisa/estudos-e-pesquisas/estudos-e-pesquisas. Acesso em: 2 set. 2020. 
MAQUEDA ABREU, María Luisa. "La violencia de género: Entre el concepto jurídico y la realidad social”. Revista Electrónica de Ciencia Penal y Criminología, n. 8, jan. 2006.

RODRIGUES, Roger de Melo. A vítima e o processo penal brasileiro: novas perspectivas. Orientador: Antonio Scarance Fernandes. 2012. 258 f. Dissertação (Mestrado) - Faculdade de Direito da Universidade de São Paulo, São Paulo, 2013. Disponível em: https://teses.usp.br/teses/disponiveis/2/2137/tde-29082013135837/publico/VERSAO_COMPLETA_DISSERTACAO_ROGER_D E_MELO_RODRIGUES_A_VITIMA_E_O_PROCESSO_PENAL_BR ASILEIRO.pdf. Acesso em: 2 set. 2020.

ROXIN, Claus. "A Teoria da Imputação Objetiva”. Chengchi Law Review, v. 58, mai. 1994.

ROXIN, Claus. Estudos de Direito Penal, Rio de Janeiro, Renovar, 2006.

SALGADO, Amanda Bessoni Boudoux; MACRI JR, José Roberto. "Raça e Violência Sexual: Âmbito de Aplicação da Vitimodogmática?". Cadernos de Estudos Sociais e Políticos, Interface entre gênero, raça e classe social, Rio de Janeiro, v. 7, n. 12, 2017.

SHECAIRA, Sérgio Salomão. Criminologia, São Paulo, Ed. Revista dos Tribunais, 2011. 
SOUZA, José Guilherme de. Vitimologia e Violência nos crimes sexuais: uma abordagem interdisciplinar, Porto Alegre, Sérgio Antonio Fabris Editor, 1998.

SYDOW, Spencer Toth. Delitos informáticos próprios: uma abordagem sob a perspectiva vitimodogmática. Orientador: Sérgio Salomão Shecaira. 2009. 282 f. Dissertação (Mestrado) - Faculdade de Direito da Universidade de São Paulo, São Paulo, 2009. Disponível em: https://teses.usp.br/teses/disponiveis/2/2136/tde-15062011161113/publico/Dissertacao_Mestrado_versao_final_formatada_padr oes_US.pdf. Acesso em: 2 set. 2020. 